\title{
Fabrication of Stair Climbing Trolley
}

\author{
Pratik Wagh $^{1}$, Krunal Shastrakar ${ }^{2}$, Keshav Tapre ${ }^{3}$, Shubham Dubey ${ }^{4}$, Prof.S.S.Pawar ${ }^{5}$ \\ ${ }^{1234}$ Students, ${ }^{5}$ Assistant Professor \\ Smt.Radhikatai Pandav Collage Of Engineering, Nagpur, India, 44032
}

Received on: 08 May,2021

Revised on: 07 June,2021

Published on: 09 June,2021

\begin{abstract}
The stair climbing trolley is developing easy mechanism for transportation of heavy loads in over stairs. The transfer of heavy load from bottom floor to top floor is very difficult by using single wheel. In production or manufacturing factory transfer by means of crane or lifting machines. The hand trolleys are used to relief the stress of lifting while on flat ground. This paper describes the research of stair climbing trolley. In civil construction sites or also in home such kinds of instrument are not in used so the transfer load on top floor is difficult. The stair climbing trolley is hand trolley to carry heavy load up the stair with less effort and with manually. In stair climbing trolley tri-star wheel is used to carry load on top floor and down the floor stairs. Also it is very low maintenance.
\end{abstract}

Keywords - hand trolley, tri-star wheel, metal frame, transportation, lifting.

\section{I- INTRODUCTION}

The goal of this project is to design and manufacture a trolley that can be use as multifunctional. The hand trolley is very common tool used by large number of factories or industries to transport heavy loads. In this trolley wheels is very important to climb a load on stair, so we use in tri-star wheel in this trolley. Also the load service is wheeled mechanism device. In stair climbing trolley more than 3 wheels are connected to the bearing shaft with a triangular plate and with straight rod. In this trolley very less effort is required to lift the loads and transfer the loads. The tri-star wheel is designed at that way the wheel is climb stair automatically. The stair climbing trolley is the simplest operating vehicle which required very less human effort without any electrical power to operate it. In this trolley must be careful not stack to high that vision is blocked and load is unstable. The load is stable when the level of load is same as level of trolley frame in same condition. This trolley is easily movable to left or right and foreword or backsword direction when load stable on the trolley.

\section{II- MAIN OBJECTIVE}

- The main objective of the trolley is to reduce or less manual effort.

- To assemble of various components to simple trolley to create a multifunctional trolley which help to climb on stair automatically.

- The trolley is designed to work on plain or rough surface.

\section{III- FABRICATION}

In this project fabrication start with making metal frame. All the frames to built perfect structure using arc welding nut-bolt fracture to convert the structure into perfect link under motion. The metals rod will cutting with cutting machine. the wheels are attached in using triangular plate on both sides of wheel alignment. the frame is brought into using appropriate using gas cutting.

The bushes, triangular plates used for wheel alignment arte grinded for smooth surface finish. After all the procedure the trolley is ready and color with paint to give good look. 


\section{International Journal of Innovations in Engineering and Science, www.ijies.net}

\section{Tri-Star Wheel}

In these trolley wheels are very important factor. Therefore tri star wheel is capable to climb over the stair. This wheel contain rotationary three tires every tire has a separate shaft. The shaft of these three tires is located on vertices of equilateral triangle. The position of equilateral triangle plate is very important for climbing. The tri star wheel can climb stair as well as obstruction inclusive of rocks and holes on roads

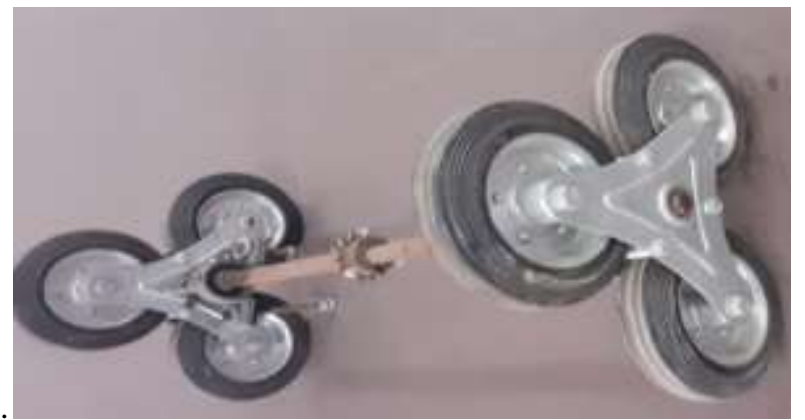

The tri -star wheel was designed by Robert and John Forsyth in 1967 for the Lockheed Aircraft Corporation

\section{IV- WORKING}

The climbing motion is made possible by the Tri-Star wheels alone. In the proposed model, the Tri-Star wheels are made of a set of three individually rotating wheels, with each individual wheel's center equidistant from the center of the web It is basically a three-socked wheel, with individual wheels attached at each end. While moving along a flat surface, two of the three wheels will be in contact with the ground surface and will roll along the ground, just as a normal wheel.The mechanism comes into action when a stair case is encountered. One of the two wheels on the ground will come in contact with the riser of the first stair. At this point of time, this wheel will not be able to rotate along its own axis. The direction of application of force. Here, the Tri-Star setup rotates, along the axis of the main hollow shaft and allows the second individual wheel, to touch the tread of the first stair.

\section{V- CONCLUSION}

The above work on fabrication design and analysis of stair climbing trolley is based on modeling made by solid works with accurate values and imported into ANSYS workbench for structural analysis and proper mesh. After performing the analysis design brought into practical working model successfully. The wheel attachment as proper gap with each other and there is no slip, 2sudden shock, wear and tear on other platform. The mechanism of transmission can carry heavy loads with less effort.

\section{REFERENCES}

[1] Mr. Pratik H. Rathod, Mr. Ravi R. Mishra, Mr. Nitin A. Waghamare, design and fabrication of stair climbing hand truck, international Journal of Emerging Trends in Engineering and Development, Issue 3, Vol.5, September, 2013

[2] Md. A.H ussain. Nafis A. Chowdhury, Rubaiat I. Linda, and Shamiuzzaman Akhtar, Design and Manufacturing of a Stair Climbing Vehicle Proceedings of the 2010 International Conference on Industrial Engineering and Operations Management,Dhaka, Bangladesh, January $9-10$, 2010.

[3] Ashish Singh, A Thesis On Design, Analysis And Fabrication Of A Reconfigurable Stair Climbing Robot, Institute Of Technology Rourkela, India, May 2015.

[4] Raj Kishor Kumar, Shahbaz, Ahmad, Shahid Khan, Shankul Behari, Shubham Rai, A Project Report On Automated Stair Climbing Wheelchair.

[5] P.Jey Praveen Raj, P.M.Mohamed Fuge, R.Paul Caleb, G.Natarajan, Design and Fabrication of Stair Climbing Trolley, internaltional journal of advancement in engineering technology,Management \&Applied science, Volume 3,Issue 5 May 2016 ISSN No;2349-3224.

[6] R.S.Khurmi, J.K.Guptha, A text book of Machine design, S.Chand publishing house $(P)$ Ltd.

[7] Dr.R.K.Bansal, A text book of Strength of materials, Laxmi Publications(P) Ltd. 